Preventable death

\section{The 1,000,000 lives campaign}

\section{F P Rivara, C Mock}

\section{Every year at least five million people around the world die from injuries - prevention of $20 \%$ of these deaths is an ambitious but feasible goal}

$\mathrm{T}$ he Institute of Medicine's report "Crossing the Quality Chasm" estimated that as many as 98,000 lives are lost each year in hospitals in the United States due to medical errors. ${ }^{1}$ In response, the Institute for Healthcare Improvement (IHI) has developed an ambitious "100,000 Lives" campaign, aimed at saving 100,000 lives each year in the US. ${ }^{2}$ The IHI is a non-profit organization that is seeking to improve health by "advancing the quality and value of healthcare". The IHI is enlisting 2000 hospitals across the US to participate in this campaign by instituting six evidenced based strategies to decrease hospital deaths: (1) rapid response teams to reverse signs of acute cardiorespiratory decline in patients and prevent cardiorespiratory arrests; (2) evidence based care for patients with acute myocardial infarctions; (3) medication reconciliation to prevent adverse drug effects; (4) prevention of central line infections through five simple interventions for care of central lines; (5) use of preoperative antibiotics to prevent surgical wound infections; and (6) prevention of ventilator associated pneumonia through four simple interventions. This 100,000 lives campaign is a voluntary activity in which hospitals sign up to participate, receive "how to" guides on each of the six topics, and share information with one another on accomplishments. Over 2500 hospitals have agreed to participate, acknowledging the fact that quality of care and patient safety are increasingly recognized by the public as important to their own individual health.

These kinds of bold, but feasible, goals have been responsible for enormous advances in the health of people around the world. The goal of eradication of smallpox was set and achieved, wiping out a scourge that existed in the world for millennia. Similar efforts are now underway to eradicate polio, to vaccinate the world's children against a variety of preventable diseases, and to develop new approaches for old problems such as malaria and tuberculosis.

\section{THE GOAL}

It is time that we in the field of injury control have our own equivalent to the "100,000 Lives" campaign. It should be a 1,000,000 lives campaign, however, and be conducted globally. There are at least five million people around the world who die annually from injuries; ${ }^{3}$ prevention of $20 \%$ of these deaths is an ambitious but feasible goal. How might this be accomplished?

\section{Modest improvements in trauma care}

Last year, the World Health Organization (WHO) published "Guidelines for Essential Trauma Care" $^{\prime 4}$ This report pointed out that there are enormous disparities in survival for trauma patients across the world, ranging from $35 \%$ in high income countries, to $55 \%$ in middle income countries, to $63 \%$ in low income countries for urban injured adults with Injury Severity Scores of 9 or greater. In rural areas, there was a sixfold difference in mortality between high and low income countries for patients with life threatening, but salvageable injuries. The report sought to establish minimum standards for core "essential trauma care services" that realistically could be provided to virtually every injured person worldwide. To assure the services, minimum essential resources are delineated, including human resources (staffing and training); physical resources (equipment, supplies), and administrative mechanisms. Reducing trauma mortality by $8 \%$ through better prehospital and trauma care (equivalent to improving trauma care to that in middle income countries) could save 400,000 lives annually.

\section{Prevention of road traffic injuries}

The World Report on Road Traffic Injury Prevention documented in detail the magnitude of the global problems of road traffic injuries and the risk factors for their occurrence. ${ }^{5}$ The report discusses the complexity of the problem, and the critical need for political will to address road traffic injuries. Despite this complexity, there are feasible interven- tions to achieve the goal of the $1,000,000$ lives campaign. These include developing an injury surveillance system, with a feedback loop to those responsible for traffic and roads; development of safe road infrastructure; setting and enforcing speed limits on both urban and rural roadways; requiring and enforcing seat belt and helmet use; and implementing and enforcing laws for driving while intoxicated. A great many of the traffic deaths globally, especially in developing countries, involve pedestrians. Prevention of pedestrian injuries has proven to be a difficult undertaking in many environments worldwide. Nonetheless, decreases of $50 \%$ or more in pedestrian death rates have been achieved through low cost environmental modifications that decrease vehicle speeds. ${ }^{67}$ These achievements in pedestrian safety, as well as the fact that seat belts decrease the risk of death by $55 \%,{ }^{8}$ and helmets decrease the risk of death in motorcycle crashes by $39 \%{ }^{9}$ and risk of brain injuries in bicycle crashes by $88 \%,{ }^{10}$ various DWI laws decrease the risk of alcohol related mortality by 5 to $15 \%,{ }^{11}$ and enforcement of traffic laws can reduce traffic deaths by $35 \%,{ }^{12}$ a $25 \%$ reduction $(300,000$ lives) in the 1.2 million road traffic deaths annually is certainly feasible.

\section{Treating depression to prevent suicide}

In 2000, an estimated 817,000 people died from suicide, making it one of the most important causes of death in the world. ${ }^{13}$ This accounted for $19,257,000$ disability adjusted life years (DALYS) lost annually. Peak mortality was in individuals 15-44 years of age. Depression affects more than 100 million people in the world each year, is the leading cause of disability, and the fourth leading contributor to the global burden of disease. Depression is the leading risk factor for suicide and treatment of depression can prevent suicidialty. ${ }^{14}$ The management of depression does not require expanded mental health services; it can be done at the primary care level. ${ }^{15}$ Such an approach appears feasible in most countries; a $20 \%$ reduction in deaths by suicide $(160,000$ lives saved) seems possible.

\section{Eliminating child labor}

There are an estimated two million work related deaths each year. ${ }^{16}$ Nearly 250 million children work. The Fair Labor Standards Act of 1938 restricted hours of work by children under age 16 in the US, and listed jobs too dangerous for workers under $18 .{ }^{17}$ The Institute of Medicine recommended updates in these regulations to further lessen the 
Table 1 Interventions to save 1,000,000 lives annually

\begin{tabular}{|c|c|c|c|}
\hline Strategy & Lives lost in 2000 & Reductions possible & Lives saved \\
\hline Improve trauma care & 5000000 & $8 \%$ & 400000 \\
\hline $\begin{array}{l}\text { Prevention of road traffic } \\
\text { injuries }\end{array}$ & 1200000 & $25 \%$ & 300000 \\
\hline Treating depression & 817000 & $20 \%$ & 160000 \\
\hline $\begin{array}{l}\text { Eliminating child labor } \\
\text { deaths }\end{array}$ & 57000 & $100 \%$ & 57000 \\
\hline $\begin{array}{l}\text { Reducing deaths from intimate } \\
\text { partner violence }\end{array}$ & 50000 & $50 \%$ & 25000 \\
\hline $\begin{array}{l}\text { Reducing child drowning } \\
\text { deaths }\end{array}$ & 116000 & $50 \%$ & 58000 \\
\hline Total & 5000000 & $20 \%$ & 1000000 \\
\hline
\end{tabular}

hazards to children. ${ }^{18}$ Nevertheless, many children and adolescents in the US and in other countries are injured while working. In one study in Brazil, $28 \%$ of children and adolescents who worked reported being injured on the job. ${ }^{19}$ In the US, a survey of teens working in agriculture found an injury rate of 15 per 100 full time equivalents per year. ${ }^{20}$ In Managua, Nicaragua nearly $3 \%$ of occupational injuries identified on emergency department surveillance occurred to children under $15 .{ }^{21}$ If this same proportion were applied to the number of fatal occupational injuries occurring in the world, 57,000 lives could be saved through the elimination of child labor.

\section{Reducing deaths from intimate partner violence}

Approximately 50,000 women die each year from interpersonal violence; many more probably die from violence but are miscoded as burns, falls, or drowning. ${ }^{13}$ Unlike in males, the vast majority of these deaths in women are the result of intimate partner violence. Physical violence to women by their partners is pervasive, with $10 \%$ to $69 \%$ of women around the world reporting being victims of physical violence by intimate partners at some point in their lives. ${ }^{22}$ Elimination of even half of these deaths would save 25,000 lives.

\section{Reducing drowning of young children}

In 2000, 116,000 children under the age of 5 drowned. Approximately one half of the worldwide deaths from drowning are to children under the age of 15 years. Following basic principles of injury prevention, environmental barriers are probably the most effective method to prevent these drownings in all countries regardless of income. Implementation of barriers in the relatively narrow circumstances of installing fencing around swimming pools in developed countries has resulted in as much as a $73 \%$ reduction in early childhood drowning fatalities. ${ }^{2324}$
Drowning in early childhood in most developing countries occurs in a wide variety of bodies of water, including wells, cisterns and other household water containers, fish ponds, irrigation ditches, rice paddies, and various natural bodies of water. ${ }^{25} 26$ The WHO advocates these same types of environmental barriers to prevent drowning in these countries; ${ }^{27}$ drowning deaths can be prevented. ${ }^{28}$ While experience with decreasing childhood drowning deaths in developing countries has been limited to date, the basic principles of low cost environmental modifications to decrease the access of young children to hazards has considerable potential. Reducing these deaths by one half would save 58,000 lives.

\section{CONCLUSION}

Prevention of 1,000,000 lives lost from injuries is within our grasp by working on these six different areas of injury control in the world. This does not require striking new research breakthroughs nor does it require redirection of enormous sums of money. It does require adopting the vision and having the will to accomplish this goal. For us in the injury control field, our job is to move beyond research studies and limited intervention trials to the larger world of public policy in order to raise the profile of injuries worldwide as a preventable problem. The strength of IHI's 100,000 lives campaign is the promotion of a package of six feasible, scientifically sound interventions that together can have a major impact on health in the US. Each of those individual interventions is well known, but few hospitals implemented all six until they were packaged together into the 100,000 lives campaign. The strength of this 1,000,000 lives campaign would lie in focusing on a single, achievable goal through the use of this set of interventions, rather than a promotion of each individually.

Injury Prevention 2005;11:321-323.

doi: 10.1136/ip.2005.009928
Authors' affiliations

F P Rivara, C Mock, Harborview Injury Prevention and Research Center, Seattle, WA, USA

Correspondence to: Dr F P Rivara, Harborview Injury Prevention and Research Center, Box 359960, 325 Ninth Ave, Seattle, WA 91804, USA; fpr@u.washington.edu

Accepted 28 August 2005

\section{REFERENCES}

1 Committee on Quality Health Care in America IoM. Crossing the quality chasm: a new health system for the 21 st century. Washington, DC: National Academies Press, 2001.

2 Institute for Healthcare Improvement. 100k lives campaign. Available at http://www.ihi.org/IHI/ Programs/Campaign/ (accessed August 2005).

3 Peden M, McGee K, Krug E. Injury: a leading cause of the global burden of disease, 2000. Geneva: World Health Organization, 2002

4 Mock C, Lormand JD, Goosen J, et al. Guidelines for essential trauma care. Geneva: World Health Organization, 2004.

5 Peden M, Scurfield R, Sleet D, et al. World report on road traffic injury prevention. Geneva: World Health Organization, 2004.

6 Ross A, Baguley C, Hills B, et al. Towards safer roads in developing countries: a guide for planners and engineers. Berkshire, England: Overseas Unit, Transport and Road Research Laboratory, 1991.

7 Afukaar F. Speed control in developing countries: issues, challanges and opportunities in reducing road traffic injuries. Inj Control Saf Promot 2003;10:77-81.

8 Cummings P, Wells JD, Rivara FP. Estimating seat belt effectiveness using matched-pair cohort
methods. Accid Anal Prev 2003;35: 143-9.

9 Norvell DC, Cummings P. Association of helmet use with death in motorcycle crashes: a matchedpair cohort study. Am J Epidemiol 2002; 156:483-7.

10 Thompson RS, Rivara FP, Thompson DC. A casecontrol study of the effectiveness of bicycle safety helmets. New Engl J Med 1989;320:1361-7.

11 Villaveces A, Cummings P, Koepsell TD, et al. Association of alcohol-related laws with deaths due to motor vehicle and motorcycle crashes in the United States, 1980-1997. Am J Epidemiol 2003;157:131-40.

12 Redelmeier DA, Tibshirani RJ, Evans L. Traffic-law enforcement and risk of death from motor-vehicle crashes: case-crossover study. Lancet 2003;361:2177-82.

13 Peden M, McGee K, Sharma G. The injury chart book: a graphical overview of the global burden of injuries. Geneva: World Health Organization, 2002.

14 Meltzer HY, Alphs L, Green Al, et al. Clozapine treatment for suicidality in schizophrenia: International Suicide Prevention Trial (InterSePT). Arch Gen Psychiatry 2003;60:82-91.

15 Katon WJ, Unutzer J, Simon G. Treatment of depression in primary care: where we are, where we can go. Med Care 2004;42:1153-7.

16 WHO. Occupational health. Vol 2005: WHO, 2005.

17 Department of Labor. Fair Labor Standards Act Available at http://www.dol.gov/esa/regs/ compliance/whd/hrg.htm\#9 (accessed August 2005).

18 Committee on the Health and Safety Implications of Child Labor National Research Council and Institute of Medicine. Protecting youth at work: health, safety, and development of working children and adolescents in the United States. Washington, DC: National Academy Press, 1998.

19 Fischer FM, Martins IS, Oliveira DC, et al. Occupational accidents among middle and high school students of the state of Sao Paulo, Brazil. Rev Saude Publica 2003;37:351-6.

20 Bonauto DK, Keifer M, Rivara FP, et al. A community-based telephone survey of work and 
injuries in teenage agricultural workers. J Agric Saf Health 2003;9:303-17.

21 Noe R, Rocha J, Clavel-Arcas C, et al. Occupational injuries identified by an emergency department based injury surveillance system in Nicaragua. Inj Prev 2004; 10:227-32.

22 Krug EG, Dahlberg LL, Mercy JA, et al. World report on violence and health. Geneva: World Health Organization, 2002.
23 Thompson DC, Rivara FP. Pool fencing for preventing drowning in children. Cochrane Database Syst Rev 2000:CD001047.

24 Langley J. Fencing of private swimming pools in New Zealand. Community Health Stud 1983;7:285-9.

25 Smith GS, Barss P. Unintentional injuries in developing countries: the epidemiology of a neglected problem. Epidemiol Rev 1991; 13:228-66.

26 Celis A. Home drowning among preschool age Mexican children. Inj Prev 1997;3:252-6.

27 World Health Organization. Facts about injuries: drowning. Geneva: WHO, 2005: 1-8.

28 Blerens J. Handbook on drowning: prevention, rescue and treatment. Heidelberg, Germany: Springer, 2004.

\section{WHO VIOLENCE PREVENTION UPDATES}

\section{TEACH-VIP: WHO's contribution to capacity building for injury prevention}

B uilding capacity is one of the main challenges facing the injury prevention area today. In many countries injuries and their prevention have been largely neglected. As a result, there are many settings around the world where public health training does not address injury related issues; medical training includes treatment of trauma but overlooks prevention; and government staff in sectors relevant to injury have neither received injury related training nor worked within structures that allow for coordinated sharing of information relevant to injury prevention.

Although the capacity building needs are varied, a clear priority is training. Accordingly, and in response to a variety of requests from governments and professional groups, the World Health Organization (WHO) has coordinated the development of TEACH-VIP, a comprehensive injury prevention and control curriculum that has been developed over three years through the efforts of WHO and a network of over 60 global injury prevention experts across 19 countries. The course material is designed around a classroom instruction model, with PowerPoint slide presentations, supporting lecture notes, and learning exercises that address a full range of topics relevant to injury prevention and control.

Among the key advantages of TEACH-VIP are the facts that the curriculum is modular and that it is distributed on CD-ROM. The modularity means diverse settings may select those lessons (from among the 60 available)

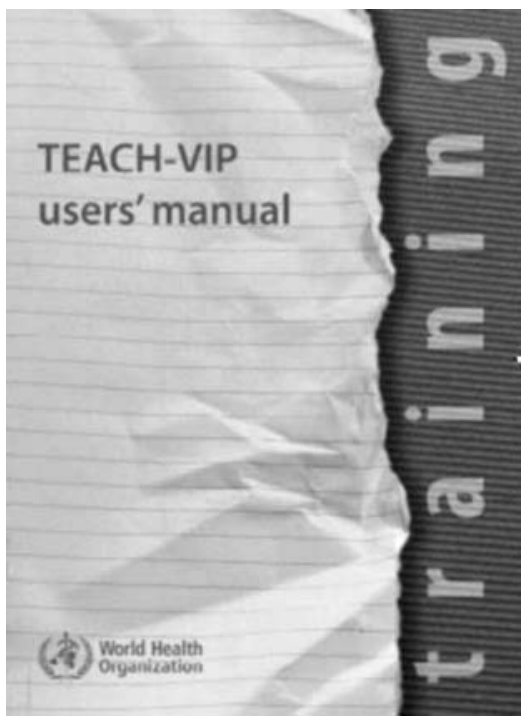

assessment of injury data; development of preventive programmes and policies; and evaluation of intervention measures. TEACH-VIP was successfully pilot tested in more than 20 settings worldwide between September 2004 and June 2005. Training audiences were varied and included government staff, medical and public health students, and injury prevention and response providers. The training materials include five questionnaires for evaluation purposes. Two important results of the evaluation are that a strong consensus exists that the materials are both of good quality and meet an important need in the various settings.

Training is only one element of capacity building. WHO will continue to strengthen the TEACH-VIP training material and its implementation, while also contributing to address other capacity building needs that fall within WHO's mandate.

TEACH-VIP was made available for that make most sense for the training audience. The dissemination as electronic files means the material may readily be adapted, with integration of local data and training examples to facilitate successful training that is relevant to participants' needs. The training materials on the CD-ROM are accompanied by a users' manual designed to provide trainers with the information necessary to make their training sessions more effective.

The lessons within TEACH-VIP cover a wide range of topics, including: application of key injury prevention and control principles; design of effective surveillance systems; collection and general distribution in September 2005. Settings that wish to receive the training packages, which include the users' manual and the TEACH-VIP CD-ROM, may register to receive these on the capacity building section of WHO's injury prevention website at www. who.int/violence_injury_prevention/.

For additional information about TEACH-VIP, contact Dr David Meddings on meddingsd@who.int.

L A Sminkey

Technical Officer, Department of Injuries and Violence Prevention, World Health Organization 